Supplement of Saf. Nucl. Waste Disposal, 1, 23-24, 2021

https://doi.org/10.5194/sand-1-23-2021-supplement

(c) Author(s) 2021. CC BY 4.0 License.

Supplement of

\title{
Development of an automated milling system for the decontamination of the wall surface in a nuclear power plant
}

Chang Li et al.

Correspondence to: Siavash Kazemi (siavash.kazemi@kit.edu)

The copyright of individual parts of the supplement might differ from the article licence. 


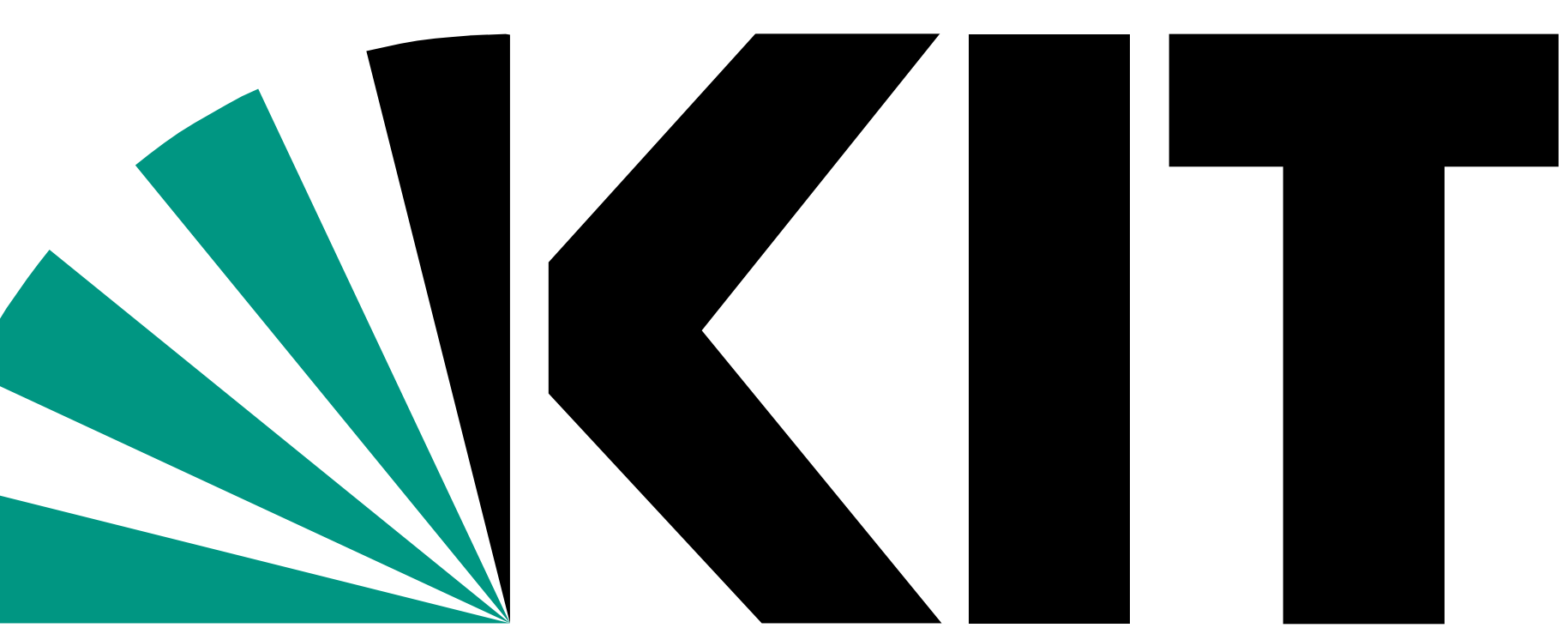

Karlsruhe Institute of Technology

\section{Development of an Automatic Milling System for the Decontamination of the Wall Surfaces in Nuclear Power Stations}

Founded by the Federal Ministry of Education and Research (BMBF)

\section{Research at KIT-TMB in ROBDEKON}

- During the reasearch project ROBDEKON the participans are working on the automatisation of the decomissioning processchain. At the moment this tasks are carried out manually.

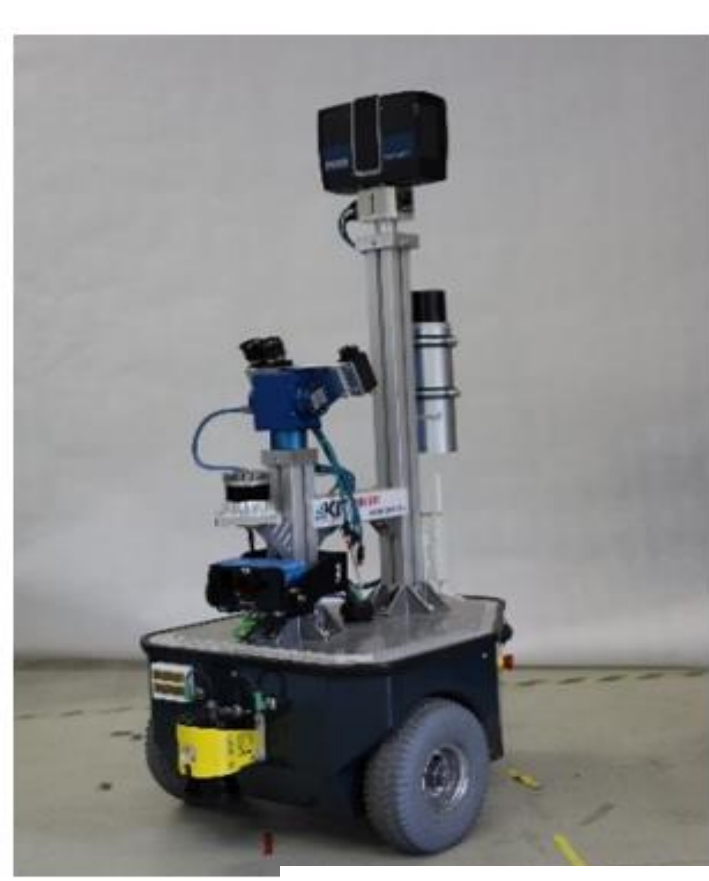

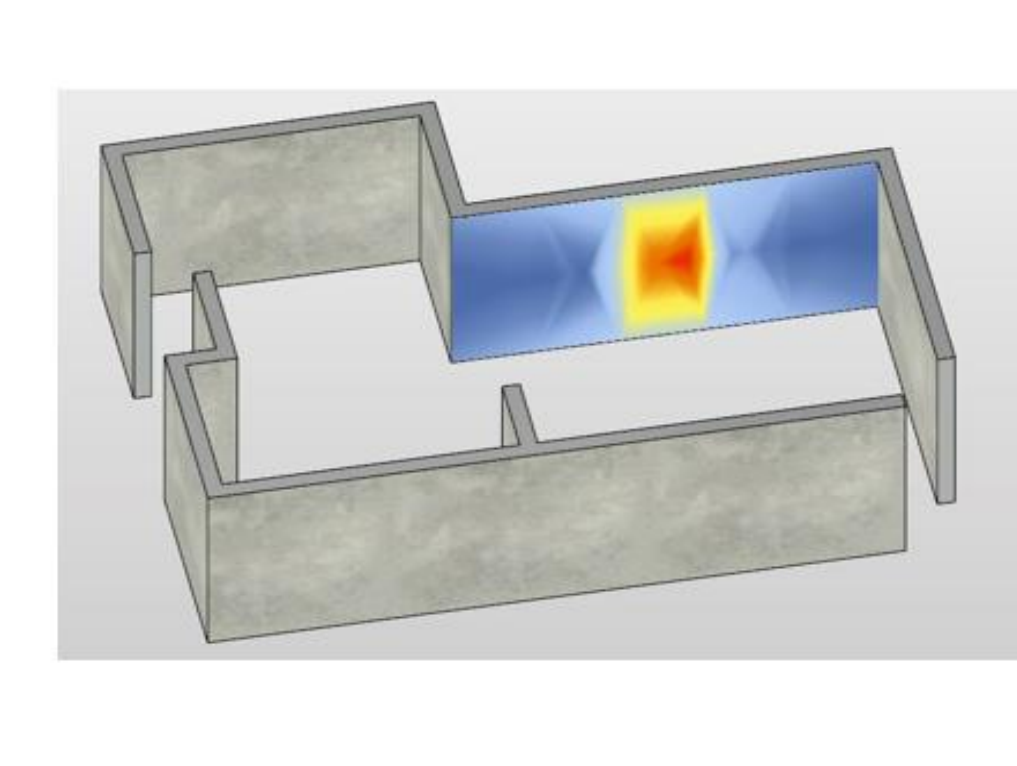

(b)

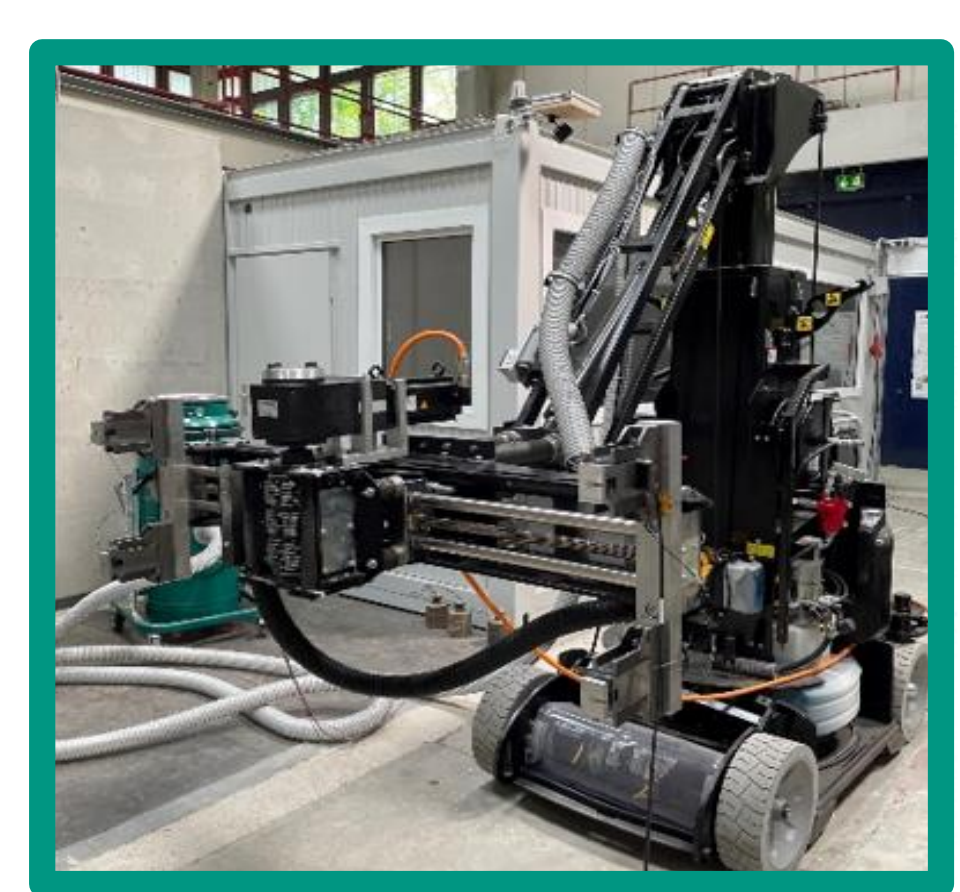

(c)

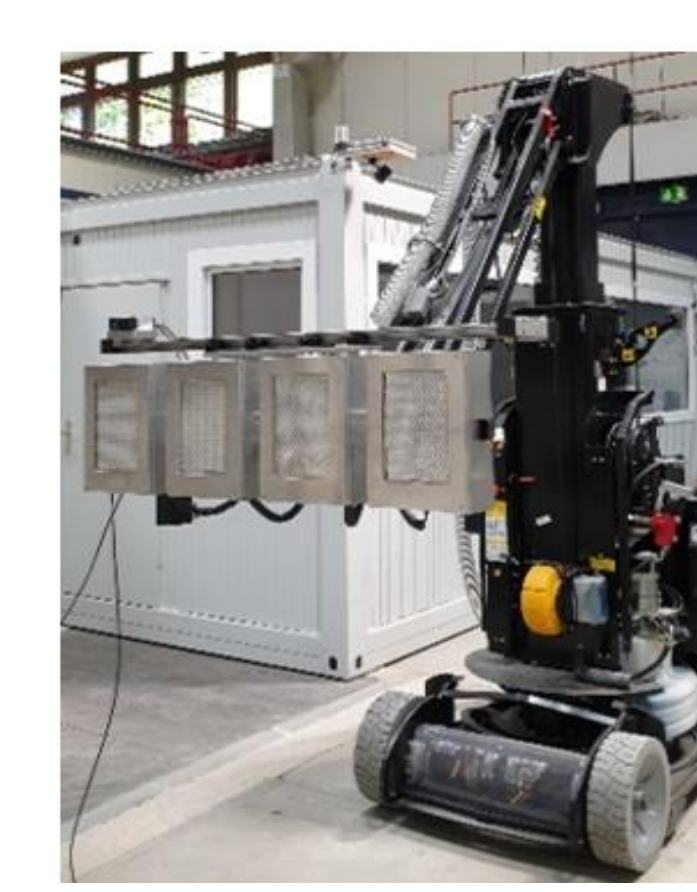

(d) (a) Autonomous environmental exploration and radiation measurement

(b) Digitalisation and modelling using BIM

(c) Automatic decontamination (mobile platform and milling tool)

(d) Automated measurement of contaminations on surfaces
2. Aim of the Automatic Milling Tool

- Disadvantages of the current approach

- Personnel deployment by machine

aided decontamination

- Monotonous work with little

communication that must be carried

out for hours

- Production of secondary waste

$\rightarrow$ Automatic Milling

of Contaminations on Flat Wall Surfaces

- Reducing of decontamination work and time

- Relief of employees and reduction of personal radiation exposure

- More flexibility to reach difficult areas using automatic mobile platform

\section{Technical Requirements and Practical Implementation}

- Automatic decontamination of wall surfaces using a milling tool with impact lamellas

- Automatic lateral motion of the milling tool using a compact DC-Motor

- Robust milling process using a speed controlled Servo-Motor

- Accurate horizontal positioning using an electro cylinder which keeps the acting force on the set value

$\rightarrow$ Measuring acting force on the tool and distance from the wall in order to perform an optimal automatic milling process

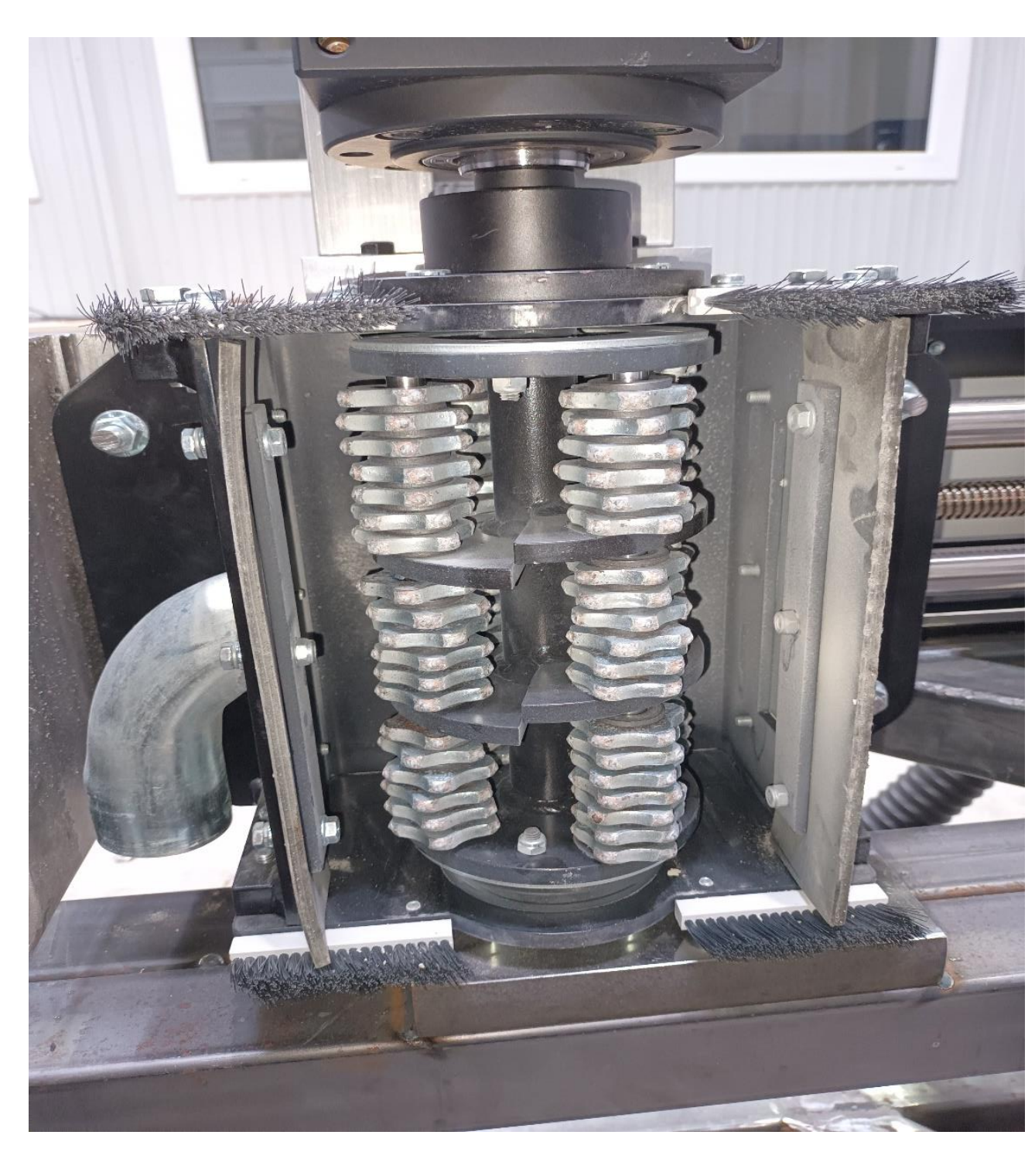

Fig. 2: Toolhead with impact lamellas

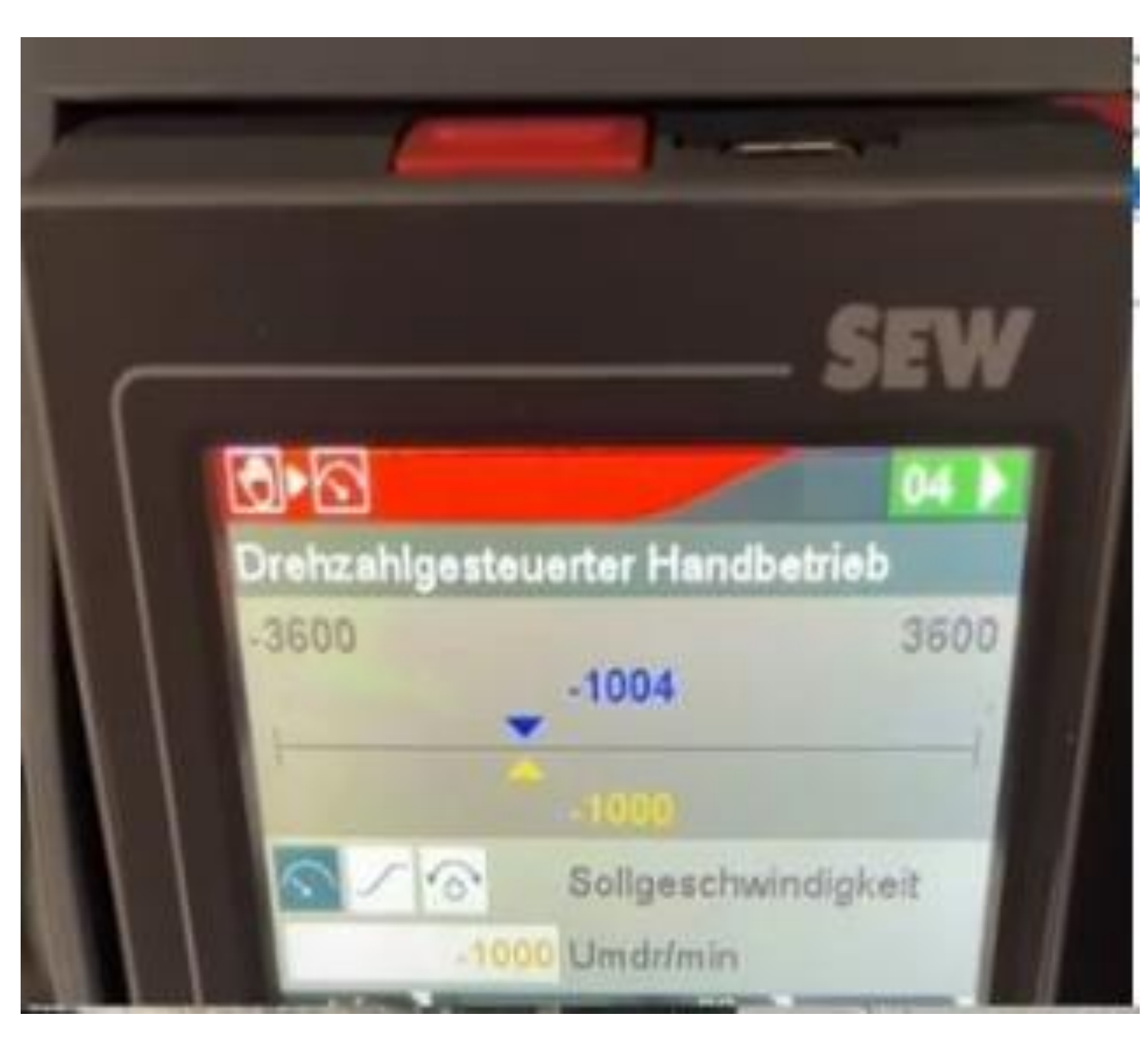

Fig. 3: Speed robustness of the Servo-Motor during the

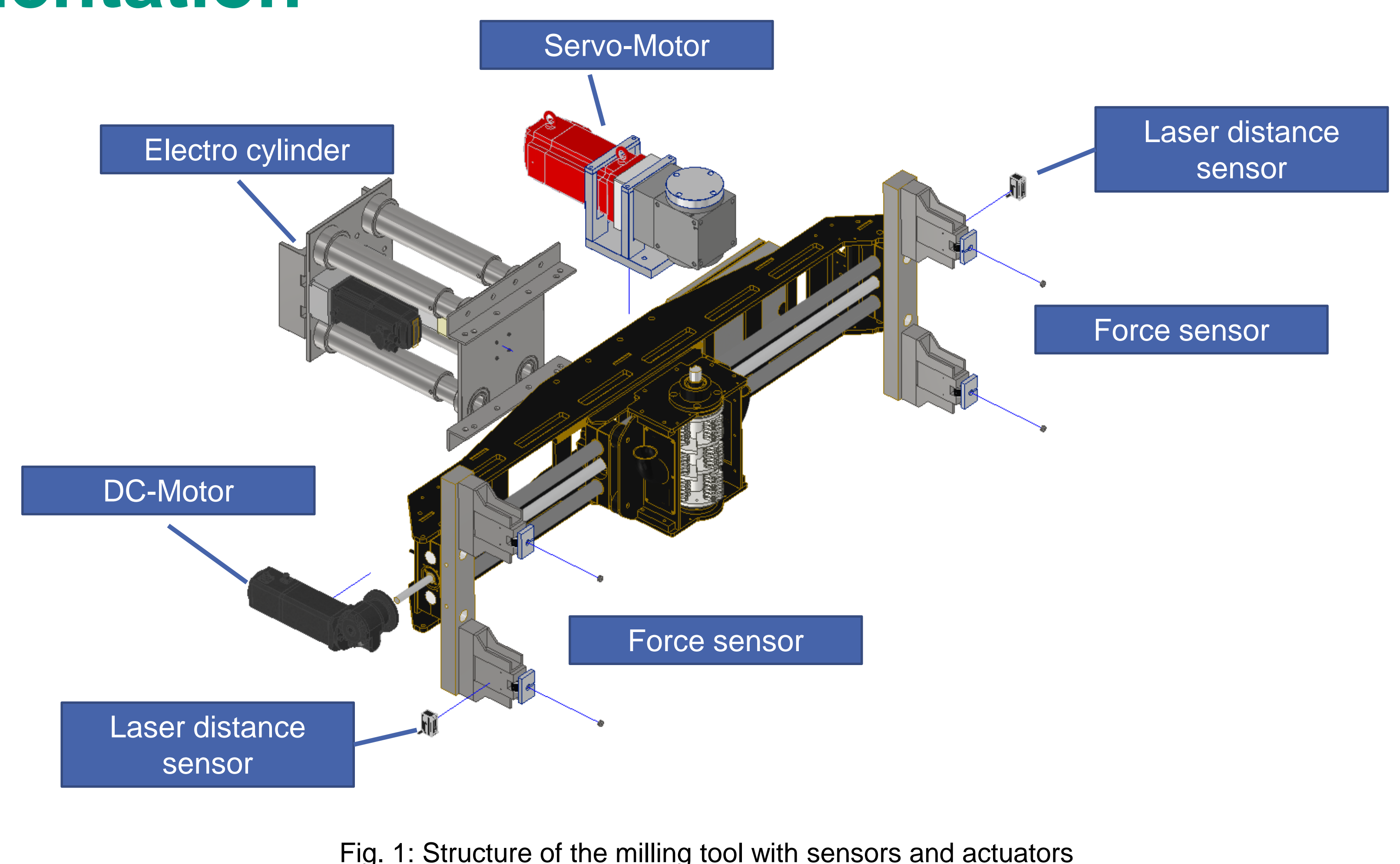

\section{Outlook}

- Automation of the robot platform to position the milling tool in a correct location

Programming the compact DC-Motor in order to automat the lateral movement

- Controller implementation for the Electro-Cylinder in order to keep the acting force on the set point

\section{Project Information}

Funding code BMBF: $13 \mathrm{~N} 14678$

Funding period: 06/2018 - 06/2022 Project partners:

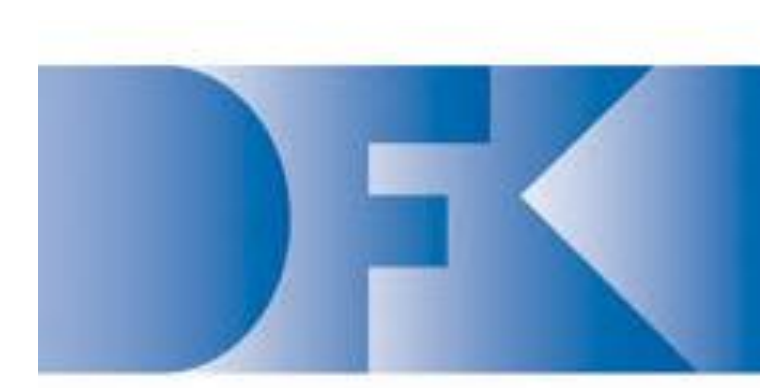

GÖTIING

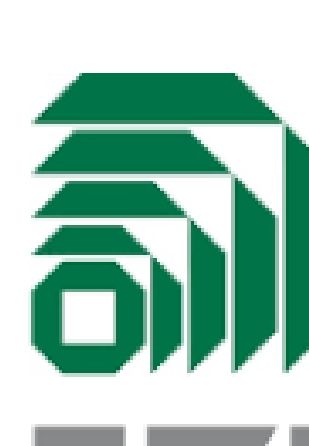

\section{Fraunhofer} IOSB
Kraftanlagen Heidelberg

\section{FZI}

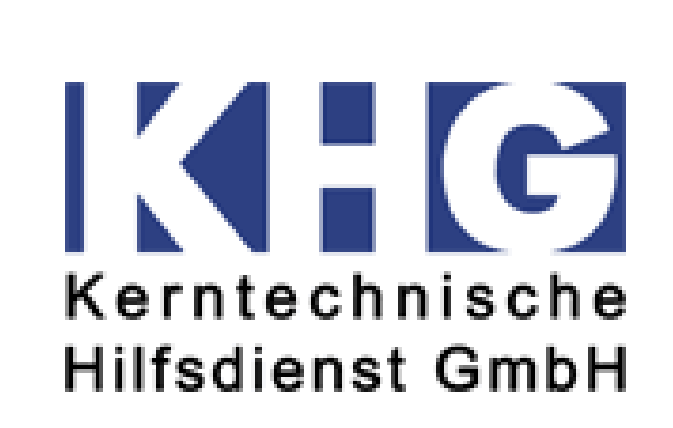

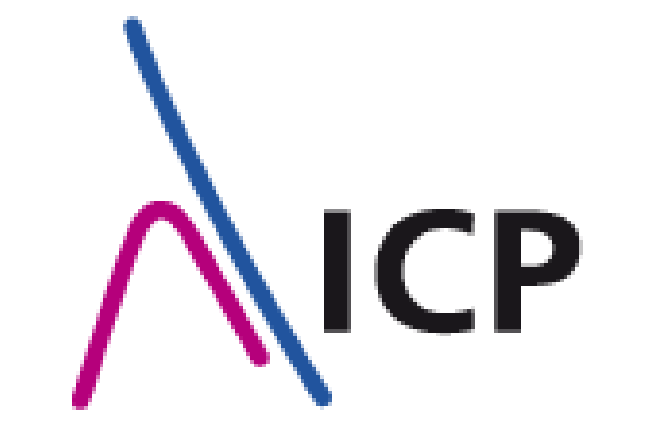

\section{Karlsruhe Institute of Technology (KIT)}

Institute of Technology and Management in Construction (TMB)

Prof. Dr.-Ing. Sascha Gentes, Tel.: +49 721 608-46546, E-Mail: sascha.gentes@kit.edu

SPONSORED BY THE

M.Sc. Siavash Kazemi, Tel.: +49 721 608-48235, E-Mail: siavash.kazemi@kit.edu 